\title{
Typical patterns of modifiable health risk factors (MHRFs) in elderly women in Germany: results from the cross-sectional German Health Update (GEDA) study, 2009 and 2010
}

Franziska Jentsch, Jennifer Allen, Judith Fuchs and Elena von der Lippe*

\begin{abstract}
Background: Modifiable health risk factors (MHRFs) significantly affect morbidity and mortality rates and frequently occur in specific combinations or risk clusters. Using five MHRFs (smoking, high-risk alcohol consumption, physical inactivity, low intake of fruits and vegetables, and obesity) this study investigates the extent to which risk clusters are observed in a representative sample of women aged 65 and older in Germany. Additionally, the structural composition of the clusters is systematically compared with data and findings from other countries.

Methods: A pooled data set of Germany's representative cross-sectional surveys GEDA09 and GEDA10 was used. The cohort comprised 4,617 women aged 65 and older. Specific risk clusters based on five MHRFs are identified, using hierarchical cluster analysis. The MHRFs were defined as current smoking (daily or occasionally), risk alcohol consumption (according to the Alcohol Use Disorders Identification Test, a sum score of 4 or more points), physical inactivity (less active than 5 days per week for at least 30 min and lack of sports-related activity in the last three months), low intake of fruits and vegetables (less than one serving of fruits and one of vegetables per day), and obesity (a body mass index equal to or greater than 30). A total of 4,292 cases with full information on these factors are included in the cluster analysis. Extended analyses were also performed to include the number of chronic diseases by age and socioeconomic status of group members.

Results: A total of seven risk clusters were identified. In a comparison with data from international studies, the seven risk clusters were found to be stable with a high degree of structural equivalency.

Conclusion: Evidence of the stability of risk clusters across various study populations provides a useful starting point for long-term targeted health interventions. The structural clusters provide information through which various MHRFs can be evaluated simultaneously.
\end{abstract}

Keywords: Lifestyle, Risk factors, Health behavior, Cluster analysis, Risk clusters, German Health Update (GEDA), Elderly women

\footnotetext{
* Correspondence: vonderLippeE@rki.de

Department of Epidemiology and Health Monitoring, Robert Koch Institute,

General-Pape-Straße 62-66, Berlin D-12101, Germany
} 


\section{Background}

The aging of populations around the world is a global phenomenon, receiving intensive examination in the context of social and demographic change. It is assumed that the factors and processes contributing to population aging will continue in the foreseeable future and will in fact accelerate over the next two decades [1]. Within the next 35 years, it is expected that the proportion of older people in the population will increase to about one-third [2]. While emerging data suggest a narrowing of the gender age gap in some countries [3], the longer life expectancy of women in most parts of the world $[4,5]$ highlights changing sex ratios associated with the process of aging. This imbalance increases with age and has been called the "feminization of age" $[6,7]$. At the same time, younger birth cohorts among the elderly show steady improvement in health. Older people today live longer, on average [8], and the additional years of life are characterized by better health $[5,9,10]$. In addition to age, sex has a substantive impact on the existence of health problems. Women have a higher prevalence of chronic diseases and disorders (e.g. osteoporosis, back pain, depression) and are affected more frequently by disability and impairment $[11,12]$.

Modifiable health risk factors (MHRFs) such as smoking, high-risk alcohol consumption, physical inactivity, low intake of fruits and vegetables, and obesity play a substantial role in mortality rates and disease incidence among the elderly $[11,13]$. According to the World Health Organization (WHO), these MHRFs are responsible for one-third of the global chronic disease burden [14] and rank among the most common risk factors leading to death in developed countries [15]. Several studies show that a "healthy" combination of MHRFs is associated with both lower morbidity rates [16-18] and lower mortality risk [19-22], and can result in substantial survival advantage.

There is evidence that MHRFs occur not only in isolation but also in specific combinations or clusters [23-34]. Different methods have been used to assess the factors associated with these risk combinations [35]. One of these methods is the application of cluster analysis. All seven of the studies examined between 1994 and 2013 that identified specific health lifestyle patterns by means of cluster analysis focused on four MHRFs: smoking, alcohol consumption, physical activity, and diet [24-26, 28, 30-32]. Only Spegel et al. [30] additionally considered body weight in their Bern-Munich Lifestyle Panel, and only one study focused on older people [28]. The results of this latter study were limited to a regional sub-sample from Baden-Württemberg, Germany and to an age range between 50 and 70 years. Obesity, however, is a serious risk factor for chronic diseases [36-38] and increased mortality [39].
A deeper understanding of the distribution of MHRFs and their combinations, and possible stabilizing relationships, should help to improve the health of older women through targeted programs of health intervention and disease prevention. This article examines typical combinations of established MHRFs in a representative sample of older women in Germany. This group in particular, because of the feminization of old age and the increased scale of medical expenses [7], forms a relevant public health population in need of study.

\section{Methods \\ Study population}

The analyses presented are based on a pooled dataset of two consecutive survey rounds (GEDA09 and GEDA10) of the German Health Update (GEDA). The GEDA study is a nationwide cross-sectional telephone survey including more than 20,000 respondents per survey round, conducted by the Robert Koch Institute (RKI) on behalf of the German Federal Ministry of Health (BMG) [40-42]. Each GEDA round was approved by The Federal Commissioner for Data Protection and Freedom of Information (BfDI), and verbal informed consent was obtained from all of the participants in advance. Information on health, healthrelated behaviors, living conditions, health-related quality of life, and socio-demographic factors was gathered. The results from GEDA are representative for communitydwelling adults in Germany who are reachable via landline [40-42]. The pooled dataset comprises a sample of 43,312 respondents aged 18 and older. The large sample allows analysis of subpopulations with further stratification by socio-demographic and health-related factors. The available weighting factors enable obtaining representative results according to sex, age, education, and region. The present study includes all female respondents aged 65 and older $(n=4,617)$. After excluding cases with missing information in the relevant variables, the total number of respondents left in the sample for cluster analysis was 4,292.

\section{Study variables}

Similar to other studies that have explored patterns of MHRFs using cluster analysis [28, 30-32], all factors in this study are dichotomized so that "1" represents the presence of the risk factor (unhealthy expression) and "0" (healthy expression) its absence (see Table 1).

\section{Smoking}

Smoking behavior was assessed by the question: "Do you currently smoke, even if it's only occasionally?" There are four possible responses: "Yes, daily," "Yes, occasionally," "No, not anymore," and "Have never smoked," from which, in line with other studies [23, 30,32,33], a dichotomous "Smoking" variable was formed. Because the group of smokers in this age group is generally very small $(10 \%)$ 
Table 1 Definitions of the five modifiable health risk factors included in the study

\begin{tabular}{ll}
\hline Risk factors & Definition of unhealthy behavior (Code $=1$ ) \\
\hline Smoking & Current smokers (includes occasional smokers) \\
Alcohol & High-risk alcohol consumption according to AUDIT-C \\
Inactivity & $\begin{array}{l}\text { Less than } 5 \text { days/week with minimum } 30 \mathrm{~min} / \text { day of } \\
\text { physical activity and no sports-related exercise within } \\
\text { past } 3 \text { months }\end{array}$ \\
Diet & Less than 1 serving of fruits or vegetables/day \\
Obesity & BMI $\geq 30 \mathrm{~kg} / \mathrm{m}^{2}$
\end{tabular}

we decided to combine the daily and occasional smokers in one category. This way the important MHRFs of smoking can be taken into account. The information on smoking includes all tobacco products.

\section{High-risk alcohol consumption}

To determine high-risk alcohol consumption in different cultural settings, the Alcohol Use Disorders Identification Test (AUDIT) was developed for the World Health Organization (WHO) [43] and was used in its short form, AUDIT-C, in GEDA09 and GEDA10 [41, 42]. The short form consists of three questions on alcohol consumption covering (1) how often the respondent drinks alcohol, (2) how many drinks are consumed on a typical occasion, and (3) how often the respondent drinks six or more alcohol units on one occasion. For interpretation, a sum score is formed with a maximum value of 12 . For women, an AUDIT-C value of 4 or more is defined as high-risk consumption [41-43]. Although an AUDIT-C score of 3 or more is often used as an indicator of hazardous drinking, several studies recommend lowering the threshold for general population samples to provide a more sensitive and specific screen [44]. Furthermore, Dawson et al. [45] and Towers et al. [46] point out that hazardous drinking prevalence in older adult populations can be overestimated using the standard threshold and suggest an older-adult-specific cut point of $4[45,46]$. This definition is applied to derive the variable "Alcohol" in the study.

\section{Physical inactivity}

Following Caspersen et al., physical activity behavior was divided into physical activity and sports [47]. These two aspects were determined in GEDA09 and GEDA10 by three questions [41, 42]. The variable "Inactivity" was formulated according to Caspersen et al. [47] as a combination of lack of physical activity defined as recommended by the Centers for Disease Control and Prevention and the American College of Sports Medicine (to be physically active less than 5 days per week for at least $30 \mathrm{~min}$ ) [48] and a lack of sports-related activity in the past 3 months. These cut-off points are in line with the WHO recommendations which suggest for adults aged 65 and older to be physical active (including leisure time activities as well as sports) between 150 and $300 \mathrm{~min}$ per week. Sports-related activity being a subset of physical activity is defined as planned, structured, and repetitive and following the goal to achieve physical fitness. Physical activity however is defined as any bodily movement produced by skeletal muscles [47].

\section{Low intake of fruits and vegetables}

Van Duyn et al. [49] provided scientific evidence that the consumption of fruits and vegetables has a preventive effect on the development of chronic diseases; therefore, the variable "Diet" as a MHRF was defined as eating less than one portion of fruit and one of vegetables per day, in general. This dichotomous variable was formed from two separate questions on consumption of fruits and vegetables [41, 42]. A portion is quantified as one handful of plant food, so that the amount consumed is adjusted to the respective constitution of the consumer [50].

\section{Obesity}

In accordance with the WHO classification, the variable "Obesity" was defined as having a body mass index (BMI) greater than or equal to $30\left(\mathrm{~kg} / \mathrm{m}^{2}\right)$ [51]. BMI was calculated from self-reported responses, namely, height: "How tall are you without shoes, in centimeters?" and weight: "How much do you weigh without clothes, in kilograms?"

\section{Additional variables}

Additional variables were included in the descriptive analysis: (1) age stratified by group (65-69, 70-74, $75-79, \geq 80$ years) and socioeconomic status (SES) in the form of a multidimensional SES index, including information on education, income and employment (SES graded as a continuous variable ranging from 3 to 21) [52]; and (2) similarly to Fuchs et al. [53], the number of chronic diseases and restrictions summed to a continuous variable of multimorbidity. Multimorbidity was determined as the presence of two or more concurrent health conditions in one person. Unlike Fuchs et al., however, obesity was not taken into account.

\section{Statistical analysis}

All analyses were performed with the statistical software SPSS, version 20 (SPSS Inc., Chicago, IL, USA). To identify distinct homogeneous groups [54] among the five MHRFs in the study population, agglomerative hierarchical cluster analysis for binary data according to the Ward method was applied [55]. To develop a deeper understanding that goes beyond the structural composition of the MHRFs, extended analyses were performed taking into account the number of chronic diseases according to age and the SES. 


\section{Results}

Distribution of modifiable health risk factors (MHRFs) and their combinations

The most prevalent MHRF among the 4,617 women aged 65 and older was "Diet" (52.3\%), followed by "Inactivity" (40.1\%); 21.3\% were obese, 18.3\% consumed alcohol in hazardous quantities, and $8.8 \%$ were current smokers (Fig. 1). Most of the older women showed at least one $(34.9 \%)$ or two (27.1\%) simultaneous MHRFs. The percentage of persons without any of the MHRFs was $17.4 \%$. The simultaneous presence of four and five MHRFs among older women occurred in $1.5 \%$ and $0 \%$, respectively (see Fig. 1). Overall, the missing information among the variables was $8.1 \%$.

\section{Description of identified risk clusters}

Using cluster analysis on the cleaned sample $(n=4,292)$, seven clusters $(C)$ of MHRFs were identified. To obtain a quick and clear impression of the cluster compositions we developed a traffic-light system, with red symbolizing unhealthy and green healthy characteristics of the relevant MHRFs. Fig. 2 illustrates the structural composition and displays percentages for the seven clusters identified, based on the five considered MHRFs. The names of the clusters are given according to the prevalence of the MHRFs within the given clusters.

The largest cluster, with $18.9 \%$ of the study population, was "C-Healthy," characterized by the absence of any MHRFs. "C-ODI" was the second largest cluster, with $17.4 \%$. Women in this cluster were obese, mostly consumed very little fruits and vegetables, and were physically inactive. "C-D" was the third largest, with $17.1 \%$, defined by only one MHRF: low consumption of fruits and vegetables. $16.5 \%$ of women were assigned to "C-A." This cluster consisted of women with high-risk alcohol consumption, and also showed partial risk behavior in terms of physical inactivity and an unhealthy diet. Whereas some of these women were also obese, all were non-smokers. In addition to the cluster of low consumption of fruits and vegetables "C-D," "C-ID" was also identified, consisting of women who on the one hand had low physical activity, and on the other ate too little fruits and vegetables and had no other MHRFs. This group included $12.2 \%$ of the study population.

"C-I" was, with 9\%, one of the smaller clusters. Members showed a deficit only in terms of adequate physical activity. Similar in size was "C-SD," with $8.9 \%$. Next to smoking, the majority of this group also had low consumption of fruits and vegetables (62\%) and low physical activity (49.6\%). A smaller number also had risk-related drinking behavior (23.1\%) and obesity (12.3\%). This cluster combined all risk factors.

The extended analyses with the number of chronic diseases according to age and the SES are plotted in Figs. 3 and 4. In both of these figures, the circles reflect the cluster size.

Fig. 3 shows that in comparison with all other clusters, the two clusters involving low physical activity (C-I and $\mathrm{C}$-ID) had the highest age range, while the "smokers" cluster C-SD ranked in a "younger" age range. In terms of age, the cluster C-ODI was located in the middle of all clusters, but included the highest average number of chronic diseases. On average, women of cluster C-A had the fewest chronic diseases.

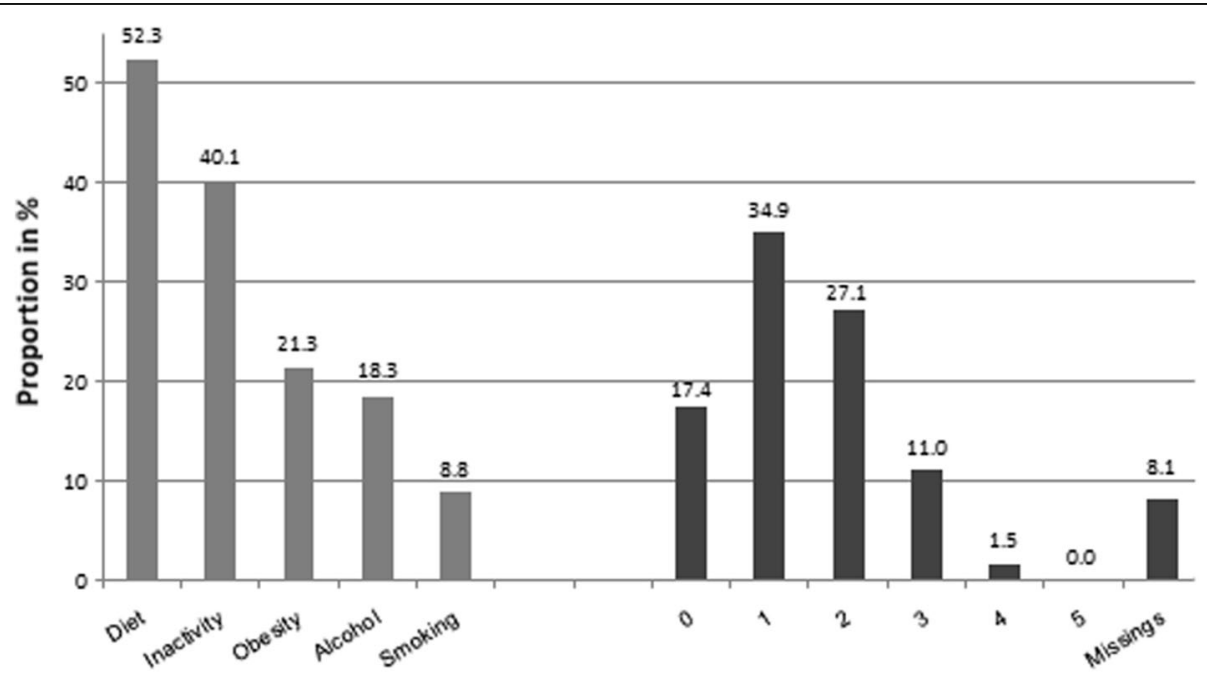

Risk factors

Number of co-existing risk factors*

Fig. 1 Distribution of risk factors in the study population and number of co-existing risk factors. ${ }^{*}$ Calculation was made only if full information for all risk factors was given, otherwise it is considered as missing 


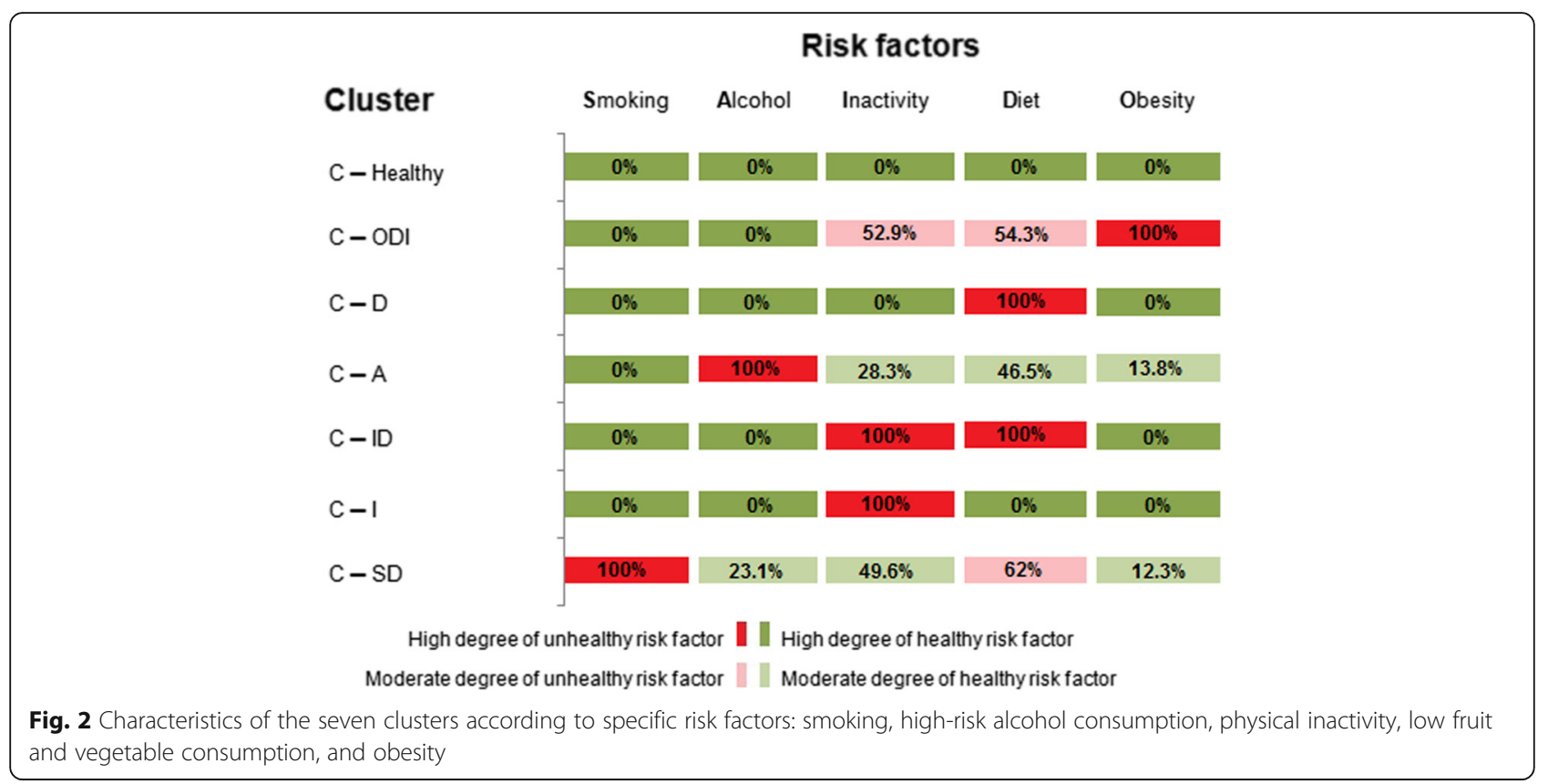

Figure 4 describes the position of the clusters in terms of the average number of chronic diseases and the average SES. After C-ID the cluster C-ODI showed the second lowest average SES, whereas the clusters CHealthy and C-A were more likely to be related to higher SES.

Further, we looked at the results from other studies to classify the identified cluster solutions. The comparisons are done with studies that have comparable methodology and examine comparable MHRFs. The sample from these studies come from Germany for population $18+[32]$, a region in Germany for a population aged
50-70 [28], a study from Ireland for population 18+ [24], a study from France for population 18+ [31], cohorts studies from the towns of Bern and Munich for population aged between 55 and 65 [30], and a US study for adults aged 21 and over [56]. For better visualization we present the outcome of the comparison in one figure (Fig. 5), which displays an overview of all overlapping identified cluster solutions of the studies considered and their structural composition. It should be noted that all of the studies differ in the approach to the MHRFs considered. For example, in line with others [28, 31, 32], we used low intake of fruits and vegetables instead of

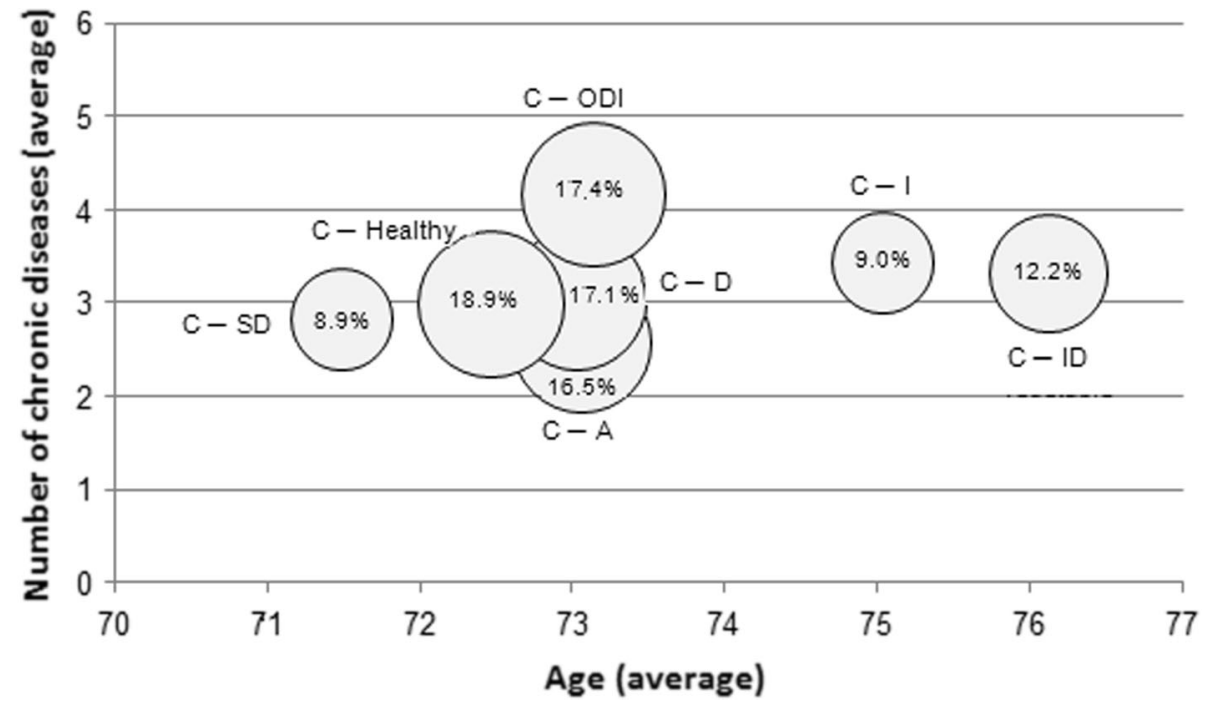

Fig. 3 Cluster characteristics according to number of chronic diseases and age 


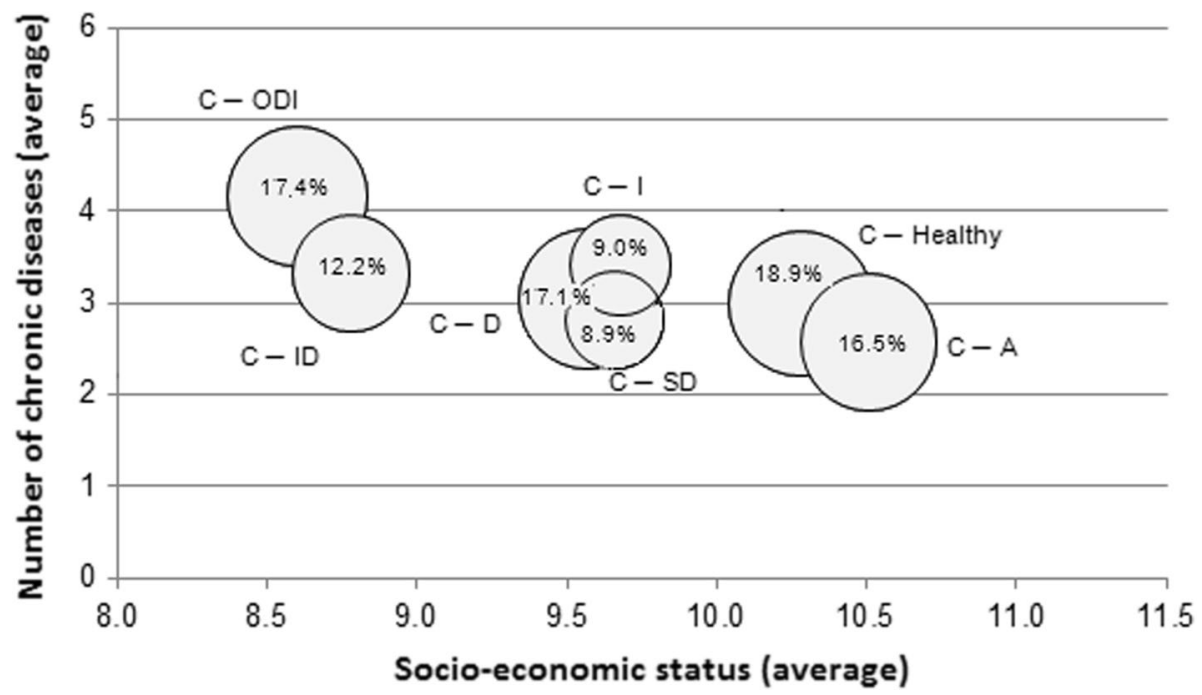

Fig. 4 Cluster characteristics according to number of chronic conditions and socioeconomic status

diet indices as one possibility to operationalize poor diet $[24,30,56]$. When the MHRF is in fact present, there are, nevertheless, differences in comparison with studies that were also limited only to consumption of fruits and vegetables.

Only Spegel et al. [30] included obesity as an additional MHRF. In contrast to the cluster C-ODI presented here, they identified two obesity clusters per study population (Munich and Bern). Because these obesity clusters differ structurally, comparable cluster solutions with obesity are missing, thus the obesity cluster is not reflected in Fig. 5.

\section{Discussion}

With the identification of seven distinct clusters of risk patterns based on the five MHRFs: Smoking, Alcohol, Inactivity, Diet, and Obesity in older women in Germany, our study shows that MHRFs tend to be associated in clusters. Six of the identified clusters show a high structural similarity to comparable studies [24, 28, 30-32, 56], inline with a recent review [35]. The clusters C-Healthy, C-A, C-I, C-SD, C-D, and C-ID have been identified in almost all studies considered here. The denomination of the cluster solutions presented by the respective authors however differs substantially from those presented in this article.

The study closest structurally to our present work is that of Schneider et al. [28], which identified a fivecluster solution, four of which match almost exactly the structural composition of our clusters (C-Healthy, C-I, C-A, and C-ID). Only within the "Smoking" cluster did Schneider et al. find a higher proportion of physical inactivity and a lower proportion of poor diet. They were unable to identify an "Unhealthy diet" cluster [28].
The above result in particular, but also the results of the other studies, demonstrates that health risk clusters based on Smoking, Alcohol, Inactivity, and Diet represent fairly stable risk patterns; that is, they are both time-stable over a period of almost 20 years and they show generally the same structure in western Europe [24, 28, 30-32] and the United States $[35,56]$. This finding serves as a useful starting point for long-term intervention programs. Health promotion programs typically aim to increase the number of years of life, but campaigns targeting older people, who typically live with multiple chronic conditions, need to emphasize quality of life as well as length of life [57]. Health programs should focus on the specific health conditions observed and the specific combinations of coexisting MHRFs present. Ideally, health intervention programs don't just target one aspect of a healthy lifestyle (for example: balanced diet), they also target the interaction between that aspect and another aspect (for example: losing weight or raising activity level).

Overall, $17.4 \%$ of the study population reported no MHRFs. In other words, in approximately four of five cases there is at least one MHRF that is not compliant with existing recommendations. Studies from the United States on adherence to health recommendations have demonstrated that education $[58,59]$ and higher income [58] have a positive influence on MHRFs, findings that can be extrapolated to our own detailed description of clusters regarding the average number of chronic diseases and SES (see Fig. 4). Women from the higher social classes are most likely to be in the cluster $\mathrm{C}$-Healthy, a fact also reported in other studies [24, 28, 30,32, 56], and is also true for cluster C-A. What most of the studies considered here have in common is that persons with higher 


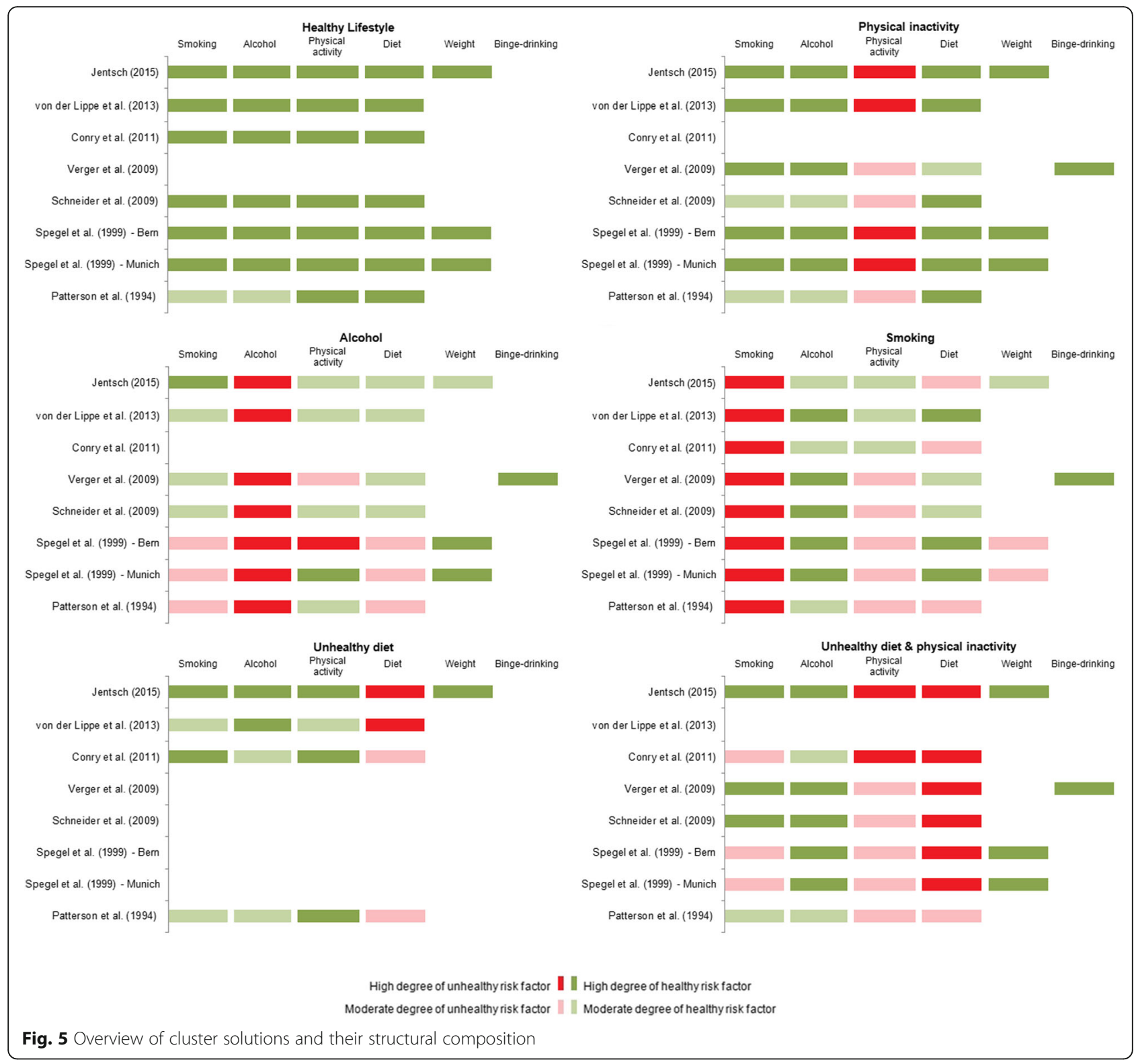

SES are found in the "Alcohol" cluster [28, 31, 32, 56]. By comparison, Spegel et al. [30] found two "Obesity" clusters, with low occupational prestige as a relevant predictor of cluster membership. Membership in the C-ODI cluster in the present study is due to a lower SES that includes professional position as one of three status dimensions. In accordance with three of the five studies that also identified the cluster C-ID, individuals of that cluster were far less likely to have a high SES $[24,30,56]$. These results show that it is necessary to consider the social inequalities of people when implementing prevention and health programs. It should be recognized that people with different social statuses generally have access to different resources, have different coping strategies, and vary in terms of health literacy [60].
Comparing the detailed descriptions of clusters with the results of similar studies showed a definite overlap. In line with the literature, the members of C-I cluster are primarily older people [32, 56]; the same was found for cluster C-ID. This result has not been reported in other studies thus far. The result showing that members of the "Smokers" cluster are younger is found often in the literature $[24,28,31]$.

The cluster "Obesity and all other risk factors" identified in the study population of Spegel et al. [30] showed that chronic diseases were positively associated with cluster membership. In our study population of older women, the probability of cluster membership also increased with the increasing number of chronic diseases, whereas it decreased for the alcohol cluster C-A (see Figs. 3 and 4). 


\section{Strengths and limitations}

One major strength of this study is the large and representative sample, based on the pooled dataset of GEDA09 and GEDA10. This allowed meaningful and reliable results for the subgroup of 65- to 100-year-old women. It is the first work of its kind that focuses solely on women in the older age group without an upper age limit.

We were not always able to clearly delineate the current recommendations regarding the definition of risky behavior. For example, the data collected in GEDA09 and GEDA10 did not include all the information necessary to define MHRFs following the current recommendations (e.g. physical inactivity). In addition, cut-off points for the MHRFs "Diet" and "Inactivity" were modified to increase the selectivity. To define high-risk alcohol consumption and obesity, only the scientific, unequivocally demonstrated risk characteristics were selected, owing to controversies regarding risk patterns. Accordingly, "never drinkers" and "overweight" were not included in the definition of risky behavior. Despite variation in the use of different health behavior measures and cut-off points between all six comparison studies, there is broad agreement within the cluster solutions. Furthermore, in the group of the smokers the occasional smokers are included which encompasses a wide range of smoking intensity.

A further limitation is the use of cross-sectional data, which meant that no causal conclusions could be drawn. Moreover, all data are based on self-reports, which are subject to systematic errors such as social desirability or recall bias. Presumably, the healthy cluster could be in reality smaller in size than found in the current study.

Finally, the results presented are valid for the specific female population aged 65 years and older, living in private households in Germany, and accessible via landline.

\section{Conclusions}

Despite the varying methods used to operationalize MHRFs and the varying age ranges that appear in the studies used in for comparison, six clusters of large structural consensus can be identified in the study populations. These clusters demonstrate that MHRFs occur both separately and in specific combinations. Such risk patterns represent a useful starting point for long-term targeted health interventions. Strategies with the aim of improving specific behaviors and MHRFs can be designed based on the structural composition of each cluster, either targeting a combination of factors (e.g., the cluster C-ID) or concentrating on individual factors (e.g., C-I).

Armed with knowledge about individual MHRFs in older women, the main focus of disease prevention should be increased physical activity and encouraging a change in diet toward increased intake of fruits and vegetables to reduce the prevalence of MHRFs and risk combinations. Furthermore, weight reduction should be an expected consequence of such positive changes. Although women from the "Alcohol" cluster seem to be the "healthiest" group with the lowest average number of chronic conditions or restrictions, it is unlikely that their good health status is a result of their risky drinking behavior. Rather, women whose health has suffered only limited damage from excessive alcohol intake may be endowed with a better genetic constitution. Given the harmful effects of high-risk alcohol consumption and its dissemination in the population of older women $(16.5 \%$ of women are part of the "Alcohol" cluster), this group should not be excluded when developing prevention programs. Because of the smaller size of the "Smoking" cluster and the lower prevalence of smoking in the study population, there is no identified need to develop a program related to smoking cessation and its coordinate risk factors.

Regarding trends in demographic change and the growing population of older women in Germany, the health and health behavior of these women has increasing relevance for intervention programs and public health in general. Further research is needed to better understand the interrelated factors of health and health behavior in older populations.

In conclusion, our results suggest that in the development of health intervention programs, priority should be given to three MHRFs: physical inactivity, obesity, and low consumption of fruits and vegetables, along with all their possible combinations.

\section{Abbreviations \\ A: Alcohol; AUDIT: Alcohol Use Disorders Identification Test; AUDIT-C: Alcohol Use Disorder Identification Test Consumption; BfDI: Federal Commissioner for Data Protection and Freedom of Information; BMG: German Federal Ministry of Health; BMI: Body Mass Index; C: Cluster; D: Diet; GEDA: German Health Update; I: Inactivity; MHRF: Modifiable Health Risk Factor; O: Obesity; RKI: Robert Koch Institute; S: Smoking; SES: Socioeconomic status; WHO: World Health Organization}

\section{Acknowledgments}

We would like to thank the study participants who responded to the survey, and all of our colleagues from the Robert Koch Institute who helped carry out the GEDA study.

\section{Funding}

There were no sources of funding for the study, for the authors, or for the manuscript preparation.

\section{Availability of data and materials}

The data from the GEDA surveys are available for public use and epidemiological research. After submitting an application form, the data are accessible from: http://www.rki.de/EN/Content/Health_Monitoring/Public_Use_Files/ public_use_file_node.htm.

\section{Authors' contributions}

FJ conceptualized the study, analyzed the data, and drafted the manuscript. JA contributed to the results, discussion, and manuscript writing. JF critically reviewed the manuscript. EVL was involved in the conception of the study and contributed to data analysis. All authors read, edited, and approved the final manuscript. 


\section{Competing interests}

The authors declare that they have no competing interests.

\section{Consent for publication}

Not applicable.

\section{Ethics approval and consent to participate}

The GEDA study was reviewed and approved by The Federal Commissioner for Data Protection and Freedom of Information in Germany. Verbal informed consent was obtained from all human subjects included in the study. Consents were obtained before conducting the telephone interviews. Interviewers informed the participants about the purpose and contents of the study and about the voluntary nature of participation. According to the German Federal Data Protection Act (FDPA), consent can be obtained other than in writing when special circumstances warrant any other form (FDPA, Section 4a, (1)). In the present study, verbal consent was applicable since the purpose of research would have been impaired considerably if consent were obtained in writing (see FDPA, Section 4a (2)). Data were collected exclusively by computer-assisted telephone interviews. No physical examination or laboratory testing was performed; biological samples were not collected.

\section{Publisher's Note}

Springer Nature remains neutral with regard to jurisdictional claims in published maps and institutional affiliations.

\section{Received: 16 January 2016 Accepted: 15 March 2017 Published online: 04 April 2017}

\section{References}

1. Lutz W, Sanderson W, Scherbov S. The coming acceleration of global population ageing. Nature. 2008;451:716-9.

2. Hoffmann E, Menning S, Schelhase T. Demografische Perspektiven zum Altern und zum Alter. [Demographic perspectives of ageing and old age.] In: Beiträge zur Gesundheitsberichterstattung des Bundes: Gesundheit und Krankheit im Alter. Berlin: RKl; 2009. p. 21-30.

3. Bennett JE, Li G, Foreman K, Best N, Kontis V, Pearson C, Hambly P, Ezzati M. The future of life expectancy and life expectancy inequalities in England and Wales: Bayesian spatiotemporal forecasting. Lancet. 2015;386:163-70.

4. Butler RN. Population aging and health. Br Med J. 1997:315:1082.

5. Doblhammer G, Kreft D. Länger leben, länger leiden? [Live longer, suffer more? Trends in life expectancy and health.]. Bundesgesundhbl Gesundheitsforsch Gesundheitsschutz. 2011;54:907-14.

6. Davidson PM, Digiacomo M, McGrath SJ. The feminization of aging: how will this impact on health outcomes and services? Health Care Women Int 2011;32:1031-45

7. Nöthen M, Böhm K. Krankheitskosten in Deutschland: Welchen Preis hat die Gesundheit im Alter? [Costs of illness in Germany: What does health in old age cost?]. In: Beiträge zur Gesundheitsberichterstattung des Bundes: Gesundheit und Krankheit im Alter. Berlin: RKl; 2009. p. 228-46.

8. Tesch-Römer C, Engstier H, Wurm S. Altwerden in Deutschland: Sozialer Wandel und individuelle Entwicklung in der zweiten Lebenshälfte: [Ageing in Germany: Social change and individual development in the second half of life. Berlin: Springer DE; 2006

9. Christensen K, Doblhammer G, Rau R, Vaupel JW. Ageing populations: the challenges ahead. Lancet. 2009;374:1196-208.

10. Jagger C, Gillies C, Moscone F, Cambois E, Van Oyen H, Nusselder W, Robine J-M. Inequalities in healthy life years in the 25 countries of the European Union in 2005: a cross-national meta-regression analysis. Lancet. 2008;372 2124-31.

11. Saß A-C, Wurm S, Ziese T. Alter= Krankheit? Gesundheitszustand und Gesundheitsentwicklung. [Age $=$ Illness? Health condition and health development.]. In: Beiträge zur Gesundheitsberichterstattung des Bundes Gesundheit und Krankheit im. Berlin: RKl; 2009. p. 31-61.

12. Kingston A, Davies K, Collerton J, Robinson L, Duncan R, Bond J, Kirkwood TBL, Jagger C. The Contribution of Diseases to the Male-female DisabilitySurvival Paradox in the Very Old: Results from the Newcastle 85+ Study. PLoS One. 2014:9:e88016.

13. Haveman-Nies A, Burema J, Cruz JAA, Osler M, van Staveren WA. Dietary Quality and Lifestyle Factors in Relation to 10-Year Mortality in Older Europeans The SENECA Study. Am J Epidemiol. 2002;156:962-8.
14. World Health Organization. The World Health report: 2002: Reducing risks, promoting healthy life. Genf, Schweiz: WHO; 2002.

15. World Health Organization. Global health risks: mortality and burden of disease attributable to selected major risks. Genf, Schweiz: WHO; 2009.

16. Ford ES, Bergmann MM, Kroger J, Schienkiewitz A, Weikert C, Boeing $\mathrm{H}$. Healthy living is the best revenge: findings from the European Prospective Investigation Into Cancer and Nutrition-Potsdam study. Arch Intern Med. 2009;169:1355.

17. Mozaffarian D, Kamineni A, Carnethon M, Djoussé L, Mukamal KJ, Siscovick D. Lifestyle risk factors and new-onset diabetes mellitus in older adults: the cardiovascular health study. Arch Intern Med. 2009;169:798-807.

18. Yusuf S, Hawken S, Ôunpuu S, Dans T, Avezum A, Lanas F, McQueen M, Budaj $A$, Pais $P$, Varigos J. Effect of potentially modifiable risk factors associated with myocardial infarction in 52 countries (the INTERHEART study): case-control study. Lancet. 2004:364:937-52.

19. Hamer M, Bates CJ, Mishra GD. Multiple health behaviors and mortality risk in older adults. J Am Geriatr Soc. 2011:59:370.

20. Khaw K-T, Wareham N, Bingham S, Welch A, Luben R, Day N. Combined impact of health behaviours and mortality in men and women: the EPICNorfolk prospective population study. PLoS Med. 2008;5:e12.

21. Knoops KB, de Groot LM, Kromhout D, Perrin A-E, Moreiras-Varela O, Menotti A, van Staveren WA. Mediterranean diet, lifestyle factors, and 10year mortality in elderly european men and women: The hale project. JAMA. 2004;292:1433-9.

22. Kvaavik E, Batty GD, Ursin G, Huxley R, Gale CR. Influence of individual and combined health behaviors on total and cause-specific mortality in men and women: the United Kingdom health and lifestyle survey. Arch Intern Med. 2010:170:711-8.

23. Chou K-L. The prevalence and clustering of four major lifestyle risk factors in Hong Kong Chinese older adults. J Aging Health. 2008;20:788-803.

24. Conry MC, Morgan K, Curry P, McGee H, Harrington J, Ward M, Shelley E. The clustering of health behaviours in Ireland and their relationship with mental health, self-rated health and quality of life. BMC Public Health. 2011; 11:692.

25. Dodd LJ, Al-Nakeeb Y, Nevill A, Forshaw MJ. Lifestyle risk factors of students: a cluster analytical approach. Prev Med. 2010;51:73-7.

26. Patterson RE, Frank LL, Kristal AR, White E. A comprehensive examination of health conditions associated with obesity in older adults. Am J Prev Med. 2004;27:385-90.

27. Poortinga $W$. The prevalence and clustering of four major lifestyle risk factors in an English adult population. Prev Med. 2007;44:124-8.

28. Schneider S, Huy C, Schuessler M, Diehl K, Schwarz S. Optimising lifestyle interventions: identification of health behaviour patterns by cluster analysis in a German 50+ survey. Eur J Public Health. 2009;19:271-7.

29. Schuit AJ, van Loon AJM, Tijhuis M, Ocké MC. Clustering of lifestyle risk factors in a general adult population. Prev Med. 2002;35:219-24.

30. Spegel $H$, Weitkunat $R$, Crispin A, Janssen C, Abel T. Muster des Gesundheitsverhaltens und ihre Determinanten-Ergebnisse des BernMünchner Lebensstilpanels. Soz Praventiv Med. 1999:44:160-70. Patterns of health-related behaviors - results from the Berne-Munich lifestyle panel.

31. Verger $\mathbf{P}$, Lions $C$, Ventelou $B$. Is depression associated with health riskrelated behaviour clusters in adults? Eur J Public Health. 2009;19:618-24.

32. von der Lippe E, Müters S, Kamtsiuris P. Risk health behavior patterns in Germany. Results from the GEDA 2009 survey. J Health Behav Pub Health. 2013:3:6-19.

33. Laaksonen M, PRÁTTALÄ R, Karisto A. Patterns of unhealthy behaviour in Finland. Eur J Public Health. 2001:11:294-300.

34. Griffin B, Sherman KA, Jones M, Bayl-Smith P. The clustering of health behaviours in older Australians and its association with physical and psychological status, and sociodemographic indicators. Ann Behav Med. 2014:48:205-14

35. Noble N, Paul C, Turon H, Oldmeadow C. Which modifiable health risk behaviours are related? A systematic review of the clustering of Smoking, Nutrition, Alcohol and Physical activity ('SNAP') health risk factors. Prev Med. 2015:81:16-41.

36. Haslam D, James WPT. Obesity. Lancet. 2005:366:1197-209.

37. Must A, Spadano J, Coakley EH, Field AE, Colditz G, Dietz WH. The disease burden associated with overweight and obesity. JAMA. 1999:282:1523-9.

38. National Institutes of Health, National Heart, Lung, and Blood Institute: Clinical guidelines on the identification, evaluation, and treatment of overweight and obesity in adults. 1998; (Effective 2002, revised 2007). 
39. Adams KF, Schatzkin A, Harris TB, Kipnis V, Mouw T, Ballard-Barbash R, Hollenbeck A, Leitzmann MF. Overweight, Obesity, and Mortality in a Large Prospective Cohort of Persons 50 to 71 Years Old. New Engl J Med. 2006; 355:763-78.

40. Lange $C$, Jentsch $F$, (shared first authorship), Allen J, Hoebel J, Kratz AL, von der Lippe E, Mueters S, Schmich P,Thelen J, Wetzstein M, Fuchs J, Ziese T: Data resource profile: German Health Update (GEDA)- the health interview survey for adults in Germany. Int J Epidemiol. 2015;44:442-50.

41. Robert Koch Institute: Daten und Fakten: Ergebnisse der Studie » Gesundheit in Deutschland aktuell 2009« [Data and Facts: Results of the "German Health Update" 2009]. Berlin: Robert Koch-Institut. 2011.

42. Robert Koch Institute: Daten und Fakten: Ergebnisse der Studie »Gesundheit in Deutschland aktuell 2010« [Data and Facts: Results of the "German Health Update" 2010]. Berlin: Robert Koch-Institut. 2012.

43. Reinert DF, Allen JP. The alcohol use disorders identification test: an update of research findings. Alcohol Clin Exp Res. 2007;31:185-99.

44. Rumpf H-J, Hapke U, Meyer C, John U. Screening for alcohol use disorders and at-risk drinking in the general population: psychometric performance of three questionnaires. Alcohol Alcohol. 2002;37:261-8.

45. Dawson DA, Grant BF, Stinson FS, Zhou Y. Effectiveness of the Derived Alcohol Use Disorders Identification Test (AUDIT-C) in Screening for Alcohol Use Disorders and Risk Drinking in the US General Population. Alcohol Clin Exp Res. 2005;29:844-54.

46. Towers A, Stephens C, Dulin P, Kostick M, Noone J, Alpass F. Estimating older hazardous and binge drinking prevalence using AUDIT-C and AUDIT-3 thresholds specific to older adults. Drug Alcohol Depend. 2011;117:211-8.

47. Caspersen CJ, Powell KE, Christenson GM. Physical activity, exercise, and physical fitness: definitions and distinctions for health-related research. Public Health Rep. 1985;100:126.

48. Pate RR, Pratt M, Blair SN, Haskell WL, Macera CA, Bouchard C, Buchner D, Ettinger W, Heath GW, King AC, et al. Physical activity and public health: A recommendation from the centers for disease control and prevention and the american college of sports medicine. JAMA. 1995;273:402-7.

49. Van Duyn MAS, Pivonka E. Overview of the health benefits of fruit and vegetable consumption for the dietetics professional: selected literature. J Am Diet Assoc. 2000;100:1511-21.

50. Rabenberg M, Mensink G: Fruit and vegetable consumption today. In: GBE kompakt: Robert Koch-Institut. 2011;2:1-9.

51. World Health Organization: Obesity: preventing and managing the global epidemic. Geneva: WHO. 2000;Report No.: 9241208945.

52. Lampert T, Kroll LE, Müters S, Stolzenberg H. Messung des sozioökonomischen Status in der Studie "Gesundheit in Deutschland aktuell" (GEDA) [Measurement of the socioeconomic status within the German Health Update (GEDA)]. Bundesgesundhbl Gesundheitsforsch Gesundheitsschutz. 2013;56:131-43.

53. Fuchs J, Busch M, Lange C, Scheidt-Nave C. Prevalence and patterns of morbidity among adults in Germany. Results of the German telephone health interview survey German Health Update (GEDA) 2009. Bundesgesundhbl. Gesundheitsforsch. Gesundheitsschutz. 2012;55:576-86.

54. Backhaus K, Erichson B, Plinke W, Weiber R. Multivariate Analysemethoden eine anwendungsorientierte Einführung [Multivariate Analysis]. Berlin: Springer; 2003.

55. Finch H. Comparison of Distance Measures in Cluster Analysis with Dichotomous Data. J Data Sci. 2005;3:85-100.

56. Patterson RE, Haines PS, Popkin BM. Health lifestyle patterns of US adults. Prev Med. 1994;23:453-60.

57. World Health Organisation. Strategy and action plan for healthy ageing in Europe, 2012 -2020. Denmark: World Health Organisation, Regional office for Europe; 2012

58. Berrigan D, Dodd K, Troiano RP, Krebs-Smith SM, Barbash RB. Patterns of health behavior in US adults. Prev Med. 2003:36:615-23.

59. Pronk NP, Anderson LH, Crain AL, Martinson BC, O'Connor PJ, Sherwood NE, Whitebird RR. Meeting recommendations for multiple healthy lifestyle factors: prevalence, clustering, and predictors among adolescent, adult, and senior health plan members. Am J Prev Med. 2004;27:25-33.

60. World Health Organisation: Health literacy. The solid facts. World Health Organisation. Regional Office for Europe; 2013.

\section{Submit your next manuscript to BioMed Central and we will help you at every step:}

- We accept pre-submission inquiries

- Our selector tool helps you to find the most relevant journal

- We provide round the clock customer support

- Convenient online submission

- Thorough peer review

- Inclusion in PubMed and all major indexing services

- Maximum visibility for your research

Submit your manuscript at www.biomedcentral.com/submit
Biomed Central 